\title{
Nest building, dimension, and selection of aromatic and medicinal twigs to repel ectoparasites in the European turtle dove
}

\author{
Ismail Mansouri * (D) | Driss Ousaaid $^{\text {(iD) }}$ | Wafae Squalli ${ }^{(i)}$ | |kram Douini ${ }^{\complement}$ |

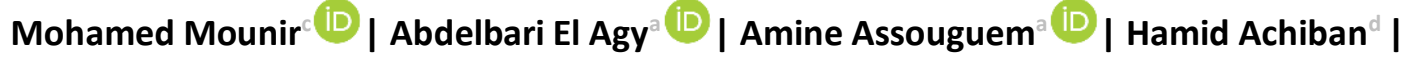 \\ Lahsen El Ghadraoui ${ }^{\circledR}$ | Mohamed Dakki
}

a Laboratory of Functional Ecology and Genie of Environment, Faculty of sciences and technology, USMBA, Fez, Morocco.

'Laboratory of Natural substances, Pharmacology Environment, Modeling, Health and quality of life. Faculty of Sciences Dhar El Mahraz, USMBA, Fez, Morocco.

Laboratory of Biotechnology and Valorisation of Phytogenetic Resources, Faculty of Sciences and Technics, Sultan Moulay Sliman University, Beni Mellal,

Morocco.

Laboratoire Milieux naturels, Aménagement et Dynamique Socio-Spatiales, Faculty of Sciences Dhar El Mahraz, USMBA, Fez, Morocco.

*Corresponding author: mankhori@gmail.com

\begin{abstract}
Studies incorporating the nesting behavior and ecology of parasite disease in the European turtle dove during breeding periods are rare. This research examined nest features and nesting materials in Turtle doves to characterize nest dimensions, build, and incorporate vegetation, mainly aromatic and medicinal plants. In parallel, we estimated the ectoparasite load on chicks to verify an eventual relation between odorant plants and pathogen loads. The study was carried in apple orchards at Okhaja Ait Ayach, Midelt province Morocco, during 2015 and 2016. The obtained results demonstrate that the Turtle dove constructs a medium nest, compared to its body size, using several plant species, including medicinal and aromatic species known for their toxicity against pathogens. The inhibition capacity of nesting materials is reflected in parasite loads since only $8 \%$ of chicks were infested with Columbicola columbae and Dermanyssus gallinae. Repellent materials in nests are a successful behavioral strategy for this declining game to protect nestlings against pathogens.
\end{abstract}

Keywords aromatic plants, ectoparasite, nest, turtle doves

\section{Introduction}

For long-distance migrant birds, nest site availability and nest construction are the main factors ensuring good breeding success (Newton 1994), where nests constitute support for eggs and nestlings and protect clutches (Mainwaring et al 2014). Research on the nest construction mainly used nesting materials is a central topic to understand the species behavioral ecology and breeding success, particularly in birds of conservation concern (Crossman et al 2011; Hansell 2000a). A bird nest is a unique construction forming a receptacle in which clutch (eggs and young) develop. The nest may be an evolutionary compromise between avian behavior and adverse environmental conditions (low temperatures and rain), keeping the eggs and nestling warm during incubation and other physical factors (Kern 1984; Kern and Van Riper 1984; Sciurine and Kern 1980). Besides, costs as the energy expended in nest building, predation risk during nest building, and nest predation due to nest conspicuousness, should be considered (Slagsvold 1984, 1989a). A nest's size is related to the birds' body size, nest type, and clutch size (Slagsvold 1982, 1989a,b). Nest-building behavior is often related to courtship and pair formation in birds because males can use nest sites and nesting material to attract a mate. The degree to which this behavior is used in courtship varies from mere manipulation of a piece of nest material, or display of a potential nest site, to the building of an entire nest by the male (Collias and Collias 1984). The actual nest-building behavior is used in displays by polygamous and monogamous bird species (Collias and Collias 1984). However, in many species, nest-building behavior is often related to protecting clutch from parasites and pathogens.

The use of the same nest sites by several breeding cohorts within one or several breeding seasons increases the risk of incurring pathogen loads (Clark and Mason 1985; Sansano-Maestre et al 2009; Schulz et al 2005). Indeed, microorganisms and parasites can lie dormant in feces and nest materials for an extended period, as they can support rough conditions, including temperatures and rain (Clark and Mason 1985). This can increase their loads in the nest and the risk of infection to birds or their nestlings (Rätti et al 1993; Robinson et al 2010). As a response, many bird species incorporate odorant vegetation and other active materials into their nests to counteract pathogens' selective pressure (Clark 1991; Fauth et al 1991; Suárez-Rodríguez et al 2013; Wimberger 1984). Chemical components in fresh vegetation or other materials found in nests may act as toxicants, repellents, or natural fumigants in controlling pathogens (Banbura et al 1995; Scott-Baumann and Morgan 2015). 
Therefore, the understanding of nesting materials and their effects on parasite loads is crucial for threatened species.

The European Turtle dove (Streptopelia turtur) is a trans-Saharan migrant, the populations that have undergone sustained and rapid declines in range and abundance, mainly in Europe (Lormée et al 2019). 93\% of the UK's Turtle dove population has declined between 1970 and 2010 (MorenoZarate et al 2020), and the species is listed as a rare bird. This decline has been essentially attributed to reducing breeding productivity (Browne and Aebischer 2004; Dunn and Morris 2012), combined with a scarcity of food resources (Browne and Aebischer 2004; Mansouri et al 2019). Concerning the infection on Turtle doves, the data are relatively rare to assess its eventual effect. Lopez (1995) found an infection rate of $50 \%$ in Spanish Doves and Lennon et al (2013) found a high incidence of trichomonad parasite infection (86\%) in UK Turtle doves, while Stockdale et al (2015) found a $100 \%$ infection rate by $T$. gallinae in adult and nestling Turtle doves in Germany. However, these studies are limited to Europe and one genus of parasites, while the defense mechanisms used by breeding Doves against these pathogens are still unexplored.

In this context, the present study aims to characterize Turtle dove nests, including their construction materials, and determine the relationship between nest materials and ectoparasite load in nestlings. In this study, we hypothesis that the parasites of chicks are sensitive to the potential repellent effect of nesting materials, particularly aromatic and medicinal plants. In parallel, nesting behavior, including nest placement and building, is targeted to characterize the vulnerable Dove's nests.

\section{Materials and Methods}

\subsection{Study area}

The present work was carried out in High Moulouya valley, at Ait Ayach zone (Midelt Province, Morocco, Figure $1)$, more especially in Oukhaja orchards $\left(32^{\circ} 41^{\prime} \mathrm{N}, 4^{\circ} 44^{\prime} \mathrm{W}\right)$. The selected site is located in relatively high altitudes (1400$1600 \mathrm{~m}$ ), in a plain dominated by apple and cereal farmlands, which offer the necessary nesting supports (trees) and food resources for breeding Turtle doves and nestlings (Mansouri et al 2019). Moreover, the climate is semi-arid, with cold winter; for the study period (2015-2017), the annual averages of temperature and rainfall were $29{ }^{\circ} \mathrm{C}$ and $89 \mathrm{~mm}$, respectively.
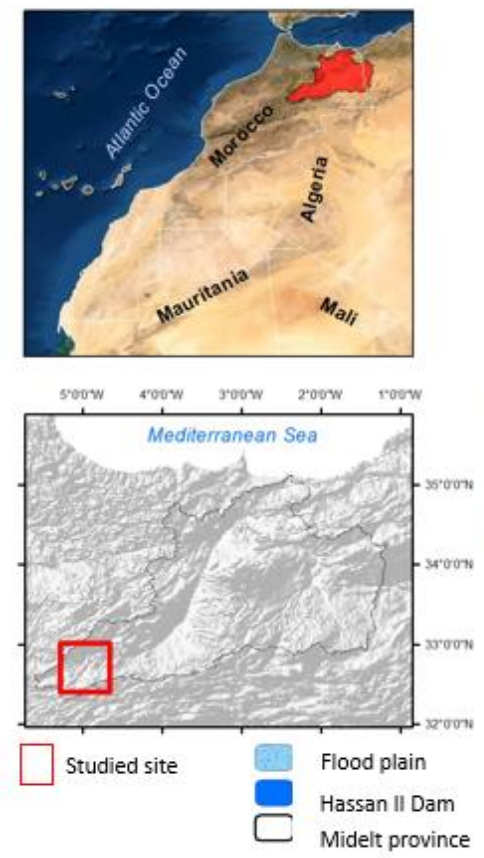

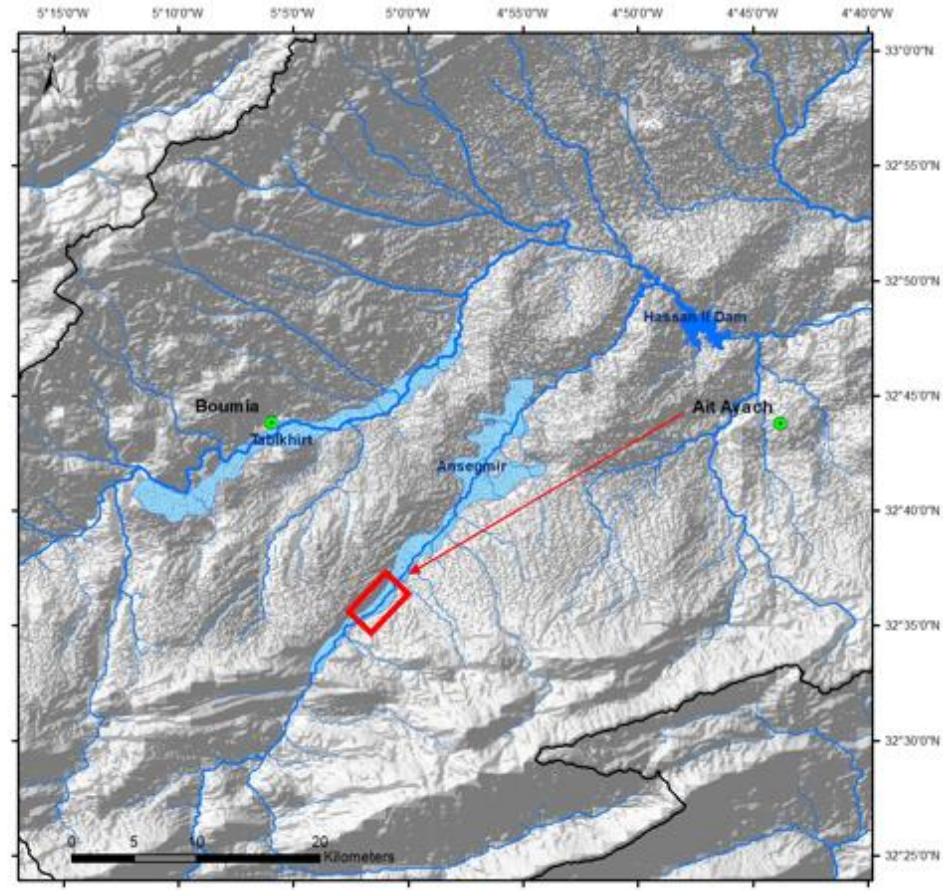

Figure 1 Breeding sites used by migrant Turtle doves in Midelt Province (Morocco) from 2015 to 2017.

\subsection{Methods}

The study was conducted in 2015 and 2016, between early April and the end of September, considering the species' breeding season as defined in this area. Data were collected in apple orchards from 84 nests identified during the 2015 season. Nest dimensions (big diameter, small diameter, and cup depth) were measured with a clinometer. Similarly, the placement of nests (concerning the center and periphery of the orchards) and their orientation were recorded at the first visit when the Doves are out of their nests. During the 2016 season, we monitored only the studied nests 2015 occupied in 2016 by breeding Doves.

For parasite load, Turtle dove chicks were monitored three times: i) the first day after hatching, ii) second visit during post-rearing ( 7 to 9 days after hatching), and ii) before chicks' emancipation (14 to 16 days after hatching), and every chick examined was ringed with numbered leg ring, weighed 
0.1g. We determined the ectoparasite load at each monitoring campaign by inspecting the chick's body between feathers and anus after the parents leave the nest for food search (Fowler and Cohen, 1983). The parasite load was limited to ectopathogens. To analyze the potential repellent effect of nesting vegetation twigs, these were preserved separately in $80 \%$ ethanol tubes and brought to the laboratory of entomology at the Faculty of Sciences and Technologies of Fez. All parasites of each tube are examined using a stereo zoom microscope and identified to the species level.

The nests monitored at the end of the 2016 breeding season were collected and brought to the laboratory. The twigs were identified in nature (plant roots, stems, or both) and taxonomies (species and family). The nesting sites' plant species were collected and identified to check if the Turtle doves choose to nest plants or use any available and abundant materials.

\subsection{Statistics}

Statistical analyses were done in STATGRAPHICS Centurion software, version XVI.I. Before running the statistical analysis, we checked for normality and homogeneity of variance for nest morphology variables with the Kolmogorov-Smirnov test. We also checked for possible correlations among Dove nests variables using Pearson's rank correlation ( $r$ ) index. The infestation rate among chicks was calculated as the number of infested chicks/all examined chicks and transformed to percentage. Finally, results were given as sample size and mean $\pm S D$.

\subsection{Ethical Note}

The study with Turtle Dove chicks conforms to the Moroccan guidelines for using animals in research and the legal requirements of the National Office of Sanitary Safety of Food Products (NOSFP). During the study, stress was minimized, and all chicks were cared for and treated appropriately, following the Moroccan laws for animal experiments. Birds used for the recording showed normal behavior and did not appear to suffer from their occasional removal from the nests. After the study, chicks left their nests successfully.

\section{Results}

\subsection{Nest characterization}

After two years of monitoring (2015-2016), 84 nests were identified and monitored. Turtle Dove nests were characterized by a big axis with $16.51 \pm 0.25 \mathrm{~cm}$, a minor axis with $13.00 \pm 0.26 \mathrm{~cm}$, and a depth of $4.59 \pm 0.15 \mathrm{~cm}$ on average. In parallel, all nest' dimensions were uncorrelated (Spearman Rank Correlations Coefficients were inferior to 0.4 , and all $P$ values were superior to 0.5$)$.

\subsection{Nest building location}

Turtle Doves built their nest mainly in the apple orchards' periphery ( $n=64$ nests) than the center $(n=20$ nests). On the other hand, the majority of nests ( $n=38$ nests) were oriented to the East, ten nests to the North, eight nests to the West, and seven nests to the Southeast, while the minority of nests were oriented between South $(n=5)$, Northwest $(n=4)$ and Southeast $(n=3)$. Besides, both parents built their nest cooperatively.

\subsection{Nesting materials and Parasite load}

In a total of 84 sampled nests, 16 nests were destroyed by farming practices inside apples) during 2015, therefore only 64 nests were analyzed. As a result, Turtle Doves used a variety of materials to build their nests. Indeed, $47.06 \%$ of nesting twigs were from plant stems, and $42.94 \%$ were mixtures of twigs, including plant stems and roots. However, in terms of plant species, we recorded twelve herbaceous species among Turtle Dove's nesting materials (Table 1), belonging to six families (Rosacea, Asteraceae, Fabaceae, Poaceae, Brassicaceae, and Polygonaceae). The most frequent were Cladanthus scariosus (recorded in 43 nests), Artemisia herba alba (23 nests), and Ononis spinosa (17 nests). Besides, many plant species were less incorporated in nesting materials, such as Rumex crispus ( 3 nests) and Rosa canina (3 nests).

Concerning the ectoparasite load, only six chicks were infested, particularly during the post-rearing phase (Table 2); however, these parasites were eliminated at the age of 16 days, probably by the parents removing pathogens and dead skin from the chicks' bodies. Two ectoparasite species were identified; Columbicola columbae on five chicks and Dermanyssus gallinae on one chick (Figure 2). On the other hand, the infestation rate was limited to $8 \%$, and breeding success was very high ( $97.33 \%$ of surviving chicks).

Two chicks died at the age of 16 days, but parasites did not infest them, and their death was linked to the nest desertion by parents due to human disturbance.

\section{Discussion}

Nest construction is a well-known behavior in several bird species, but we have relatively little information about the species-specific nests (Walsh et al 2010). Similarly, despite being a widespread and threatened species, little is known about Turtle Doves' nesting features, mainly in North Africa.

Based on a sample of 84 nests, our field research indicates that Turtle doves built a medium-size nest, suggesting an appropriate relation between nest morphology and Dove's size (Biddle et al 2015; Hanane 2010). This conclusion is now verified in many species that construct nests with a high variety of shapes (scrapes, cups, domes, burrows, among others) and a wide range of sizes, in correlation with their body size (Collias and Collias 1984; Hansell 2000b), the predation risk and, occasionally, with environmental conditions that could affect nestling, knowing that the nests are the principal support to the clutches 
(Biddle et al 2015; Mainwaring et al 2014; Walsh et al 2010). This nesting behavior allows bird species to reduce building costs. Furthermore, in the Midelt apple orchards, Turtle doves orient their nests, mainly to the eastern direction, probably to protect them against the frequent Western winds and to ensure better exposition to the sun. This behavioral strategy was demonstrated in Tree Pipit (Anthus trivialis), which orients its nests to the East to avoid western wind and benefit from solar radiation during the morning to warm up nestling.

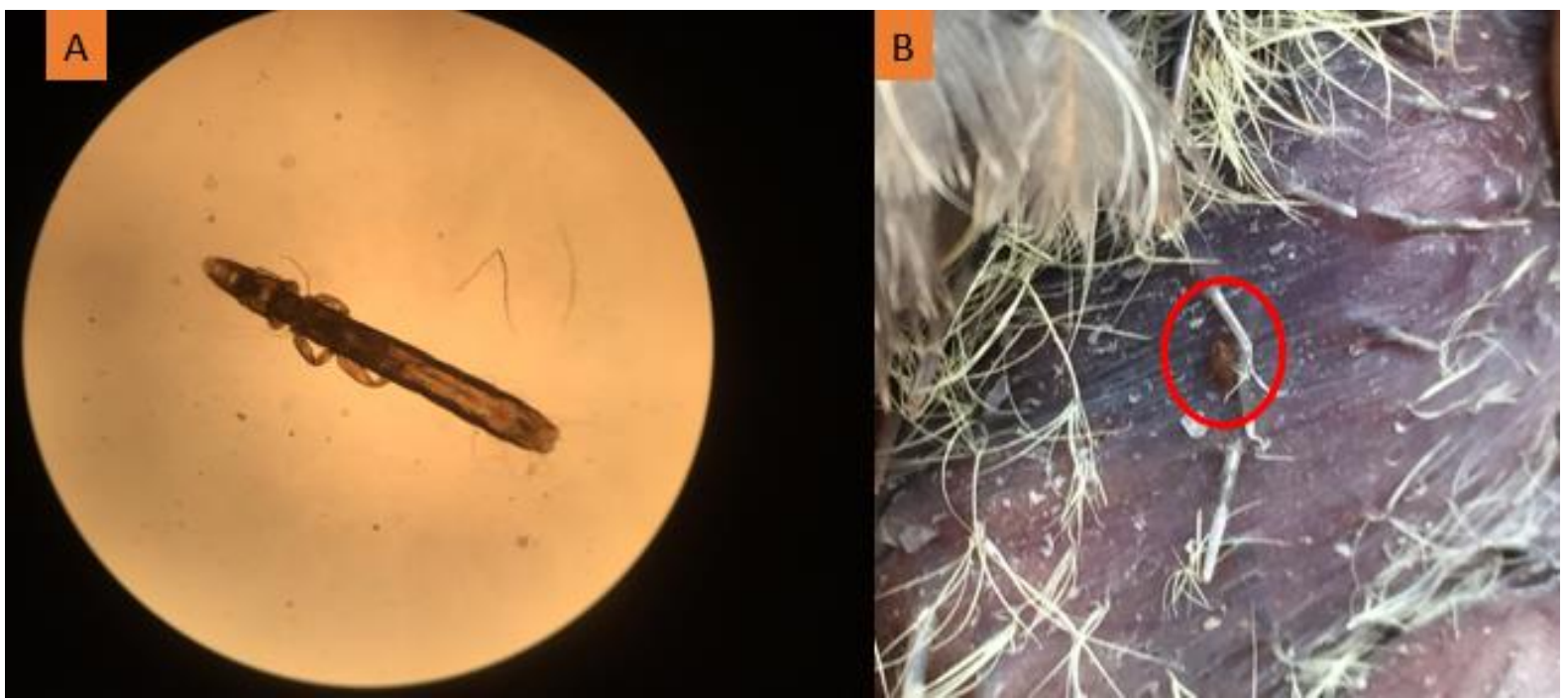

Figure 2 Parasites identified on Turtle Dove chicks' body. A) Columbicola columbae and B) Dermanyssus gallinae.

Table 1 Plant species identified in nesting materials of European Turtle doves.

\begin{tabular}{lllc}
\hline Common name & Scientific name & Family & $\begin{array}{c}\text { Number on nests } \\
\text { incorporating plant species }\end{array}$ \\
\hline $\begin{array}{l}\text { Undefined } \\
\text { White wormwood }\end{array}$ & Cladanthus scariosus & Rosacea & 43 \\
Alfalfa or lucerne & Artemisia herba alba & Asteraceae & 23 \\
Foxtail barley & Ononis spinosa & Fabaceae & 17 \\
Hedicago sativa & Fabaceae & 15 \\
Hare barley & Hordeum jubatum & Poaceae & 12 \\
Common barley & Hordeum vulgare & Poaceae & 12 \\
Rocket salad & Eruca sativa & Poaceae & \\
Wall rocket & Diplotaxis muralis & Brassicaceae & 9 \\
Bridal broom & Retama monosperma & Brassicaceae & 9 \\
Dog rose & Fosa canina & Rosaceae & 8 \\
Curled dock & Rumex crispus & Polygonaceae & 6 \\
\hline
\end{tabular}

Table 2 Parasite load during the growth period of Turtle Dove chicks and success rate.

\begin{tabular}{lccc}
\hline Parameters & Hatching-phase & Post-rearing-phase & Before fight-phase \\
\hline Nestling age & First day & $7-9$ days & $14-16$ days \\
Ectoparasite load & 0 & 6 & 0 \\
Success rate & $75(100 \%)$ & $75(100 \%)$ & $73(97.33 \%)$ \\
\hline
\end{tabular}

In the nests of Midelt, thirteen plant species belonging to six families were identified. This diversity of materials could be attributed to two factors: the diversity in vegetation surrounding the breeding sites and/or a potential role in protecting the nestlings against pathogens. Concerning the first suggestion, many other plant species (Rosmarinus Officinalis, Stipa Tenacissima, Leontodon Hispidus, Biscutella Didyma, and 23 other species) were abundant in/and around apple orchards without being incorporated into the nests. This indicates a behavioral pattern in selecting nest materials, while our study supports the hypothesis of choosing plants that likely could protect nestlings. Despite the absence of statistical evidence, an extensive literature attributes a powerful repulsive impact on pathogens to some species that were incorporated in $89.28 \%$ of nests and the low rate of infestation (8\%) in chicks: Cladanthus scariosus, Artemisia herba-alba, Rosa canina, and Retama monosperma (Segal et al 1987;Wenzig et al 2008; Mighri et al 2010; Mohamed et al 2010; El Hamdani et al 2018; Jafarirad et al 2016;Ousaaid et al 2020; Rovná et al 2020; Spadaro et al 2014). 
Moreover, Lennon et al (2013) and Stockdale et al (2015) found a $100 \%$ infection rate by $T$. gallinae in adult and nestling Turtle Doves, with clinical signs, while in the present study, where repellent twigs were incorporated, infestation rate was at only $8 \%$, by two ectoparasites Columbicola columbae and Dermanyssus gallinae. Indeed, the identified plant materials contain volatile secondary compounds, such as hydrocarbons (mainly monoterpenes and isoprene) which could have biocidal effects on parasites and pathogens (Clark 1991; Dubiec et al 2013). Thus, this strategy would help the Midelt Turtle doves to reduce parasite loads and to ensure a better breeding success; this avoids any future decline as that recorded in Europe.

\section{Conclusions}

In the high altitude apple orchards of the Midelt region, the nests of Turtle dove are of medium-size compared to their body size and have an eastern orientation preferably. They use diverse nesting materials, mainly plant twigs and stems. Far from being simple physical support for eggs and chicks, Dove nests contain plants that are well-known as a repellent and/or toxic to ectoparasites, ensuring maximum protection to nestlings against ectopathogens. The species seems to choose such 'medicinal' plants, among several other species around the nesting sites.

Further, more deep studies are needed to verify if such plants also impact the endoparasites and if this impact increases Turtle Dove nestlings' survival. Investigating how this species behaves in more natural and artificial Mediterranean habitats is also required to determine pathogens' cost on the Turtle dove population.

\section{Conflict of Interest}

The authors declare that there are no conflict of interest with this work.

\section{Funding}

This research did not receive any financial support.

\section{References}

Banbura J, Blondel J, de Wilde-Lambrechts H, and Perret P (1995) Why do female Blue Tits (Parus careuleus) bring fresh plants to their nests? Journal Für Ornithologie 136:217-221.

Biddle LE, Broughton RE, Goodman AM, and Deeming DC (2018) Composition of Bird Nests is a Species-Specific Characteristic. Avian Biology Research 11:132-153.

Biddle LE, Deeming DC, and Goodman AM (2015) Morphology and biomechanics of the nests of the Common Blackbird Turdus merula. Bird Study 62:87-95.

Browne SJ, and Aebischer NJ (2004) Temporal changes in the breeding ecology of European Turtle Doves Streptopelia turtur in Britain, and implications for conservation. Ibis 146:125-137.

Burton NHK (2006) Nest orientation and hatching success in the tree pipit Anthus trivialis. Journal of Avian Biology 37:312-317.

Clark L (1991) The nest protection hypothesis: the adaptive use of plant secondary compounds by European starlings. Bird-Parasite Interactions: Ecology, Evolution and Behaviour. Oxford University Press, Oxford 205-221.

Clark L, and Mason JR (1985) Use of nest material as insecticidal and anti- pathogenic agents by the European starling. Oecologia 67:169-176.

Collias NE, and Collias EC (1984) Nest building and bird behavior (Princeton University Press).

Crossman CA, Rohwer VG, and Martin PR (2011) Variation in the structure of bird nests between northern Manitoba and southeastern Ontario. PLoS One 6:e19086.

Deeming DC (2013) Effects of female body size and phylogeny on avian nest dimensions. Avian Biology Research 6:1-11.

Deeming DC, Mainwaring MC, Hartley IR, and Reynolds SJ (2012) Local temperature and not latitude determines the design of Blue Tit and Great Tit nests. Avian Biology Research 5:203-208.

Dubiec A, Góźdź I, and Mazgajski T (2013) Green plant material in avian nests. Avian Biology Research 6:133-146.

Dunn JC, and Morris AJ (2012) Which features of UK farmland are important in retaining territories of the rapidly declining Turtle Dove Streptopelia turtur? Bird Study 59:394-402.

El Hamdani N, Filali-Ansari N, Zefzoufi M, Derhali S, El Abbouyi A, El Khyari S, Mouzdahir A, Sraidi K, Harjane T, Fdil R (2018) Preliminary phytochemical analysis and antibacterial potential of organic extracts from aerial parts of Retama monosperma.

Fauth PT, Krementz DG, and Hines JE (1991) Ectoparasitism and the role of green nesting material in the European starling. Oecologia 88:22-29.

Fowler JA, and Cohen S (1983) A method for the quantitative collection of ectoparasites from birds. Ringing \& Migration 4:185-189.

Hanane S (2010) Biométrie des tourterelles des bois Streptopelia turtur dans le sud du Maroc (région de Taroudant). Ecologia Mediterranea 36:107-110.

Hansell M (2000) Bird nests and construction behaviour (Cambridge University Press).

Jafarirad S, Mehrabi M, Divband B, and Kosari-Nasab M (2016) Biofabrication of zinc oxide nanoparticles using fruit extract of Rosa canina and their toxic potential against bacteria: A mechanistic approach. Materials Science and Engineering: C 59:296-302.

Kern MD (1984) Racial Differences in Nests of White-Crowned Sparrows. The Condor 86:455-466.

Kern MD, and Van Riper C (1984) Altitudinal Variations in Nests of the Hawaiian Honeycreeper Hemignathus virens virens. The Condor 86:443-454.

Lennon RJ, Dunn JC, Stockdale JE, Goodman SJ, Morris AJ, and Hamer KC (2013) Trichomonad parasite infection in four species of Columbidae in the UK. Parasitology 140:1368-1376.

Lopez EM (1995) Estudio de la prevalencia y susceptibilidad a la infeccion por t. Gallinae en aves domesticas y silvestres. Valoracion de la sensibilidad del protozoo a diferentes derivados nitroimidazolicos.

Lormée H, Barbraud C, Peach W, Carboneras C, Lebreton JD, Moreno-Zarate L, Bacon L, and Eraud C (2019) Assessing the sustainability of harvest of the European Turtle-dove along the European western flyway. Bird Conservation International 1-16.

Mainwaring MC, Hartley IR, Lambrechts MM, and Deeming DC (2014) The design and function of birds' nests. Ecology and Evolution 4:3909-3928.

Mansouri I, Al-Sadoon MK, Rochdi M, Paray BA, Dakki M, and Elghadraoui L (2019) Diversity of feeding habitats and diet composition in the turtle doves Streptopelia turtur to buffer loss and modification of natural habitats during breeding season. Saudi Journal of Biological Sciences 26:957-962.

Mighri H, Hajlaoui H, Akrout A, Najjaa H, and Neffati M (2010) Antimicrobial and antioxidant activities of Artemisia herba-alba essential oil cultivated in Tunisian arid zone. Comptes Rendus Chimie 13:380-386.

Mohamed AE-HH, El-Sayed M, Hegazy ME, Helaly SE, Esmail AM, and Mohamed NS (2010) Chemical constituents and biological activities of Artemisia herba-alba. Records of Natural Products 4.

Moreno-Zarate L, Estrada A, Peach W, and Arroyo B (2020) Spatial heterogeneity in population change of the globally threatened European turtle dove in Spain: The role of environmental favourability and land use. Diversity and Distributions. 
Muno LE (1998) estudio de la prevalencia y susceptibilidad a la infecci \'on por $\{\backslash$ it trichomonas gallinae $\backslash\}$ en aves dom\'esticas y silvestres: valoraci\'on de la sensibilidad del protozoo a diferentes derivados nitroimidazolicos.

Newton I (1994) The role of nest sites in limiting the numbers of hole-nesting birds: a review. Biological Conservation 70:265-276.

Ousaaid, D, Mansouri I, Laaroussi H, ElGhouizi A, Lyoussi B, and ElArabi I (2020) Phytochemical Content and Antioxidant Activity of Flesh Fruits Rosa canina Extracts Collected from Ait Ayach Midelt. Indian Journal of Agricultural Research 54.

Rätti O, Dufva R, and Alatalo RV (1993) Blood parasites and male fitness in the pied flycatcher. Oecologia 96:410-414.

Robinson RA, Lawson B, Toms MP, Peck KM, Kirkwood JK, Chantrey J, Clatworthy IR, Evans AD, Hughes LA, and Hutchinson OC (2010) Emerging infectious disease leads to rapid population declines of common British birds. PLoS One 5:e12215.

Rovná K, Petrová J, Terentjeva M, Černá J, and Kačániová M (2020) Antimicrobial activity of Rosa canina flowers against selected microorganisms. Journal of Microbiology, Biotechnology and Food Sciences 9:62-64.

Sansano-Maestre J, Garijo-Toledo MM, and Gómez-Muñoz MT (2009) Prevalence and genotyping of Trichomonas gallinae in pigeons and birds of prey. Avian Pathology 38:201-207.

Schulz JH, Bermudez AJ, and Millspaugh JJ (2005) Monitoring presence and annual variation of trichomoniasis in mourning doves. Avian Diseases 49:387-389.

Sciurine C, and Kern M (1980) The insulation in nests of selected North American songbirds. Auk 97:816-824.

Scott-Baumann JF, and Morgan ER (2015) A review of the nest protection hypothesis: does inclusion of fresh green plant material in birds' nests reduce parasite infestation? Parasitology 142:1016-1023.
Segal R, Feuerstein I, and Danin A (1987) Chemotypes of Artemisia herbaalba in Israel based on their sesquiterpene lactone and essential oil constitution. Biochemical Systematics and Ecology 15, 411-416.

Slagsvold T (1982) Clutch Size, Nest Size, and Hatching Asynchrony in Birds: Experiments with the Fieldfare (Turdus Pilaris) 63:1389-1399.

Slagsvold T (1984) Clutch Size Variation of Birds in Relation to Nest Predation: On the Cost of Reproduction. Journal of Animal Ecology 53:945-953.

Slagsvold T (1989a) On the evolution of clutch size and nest size in passerine birds. Oecologia 79:300-305.

Slagsvold T (1989b) Experiments on clutch size and nest size in passerine birds. Oecologia 80:297-302.

Spadaro V, Raimondo F, Fennane M, Bruno M, and Senatore F (2014). Chemical composition of the essential oil of cladanthus scariosus (asteraceae) wild grown in Morocco. In Societa Botanica Italiana $109^{\circ}$ Congresso International Plant Science Conference (IPSC) from Nature to Technological Exploitations 142-142.

Stockdale JE, Dunn JC, Goodman SJ, Sheehan AJ, Sheehan DK, Grice PV, and Hamer KC (2015) The protozoan parasite Trichomonas gallinae causes adult and nestling mortality in a declining population of European Turtle Doves, Streptopelia turtur. Parasitology 142:490-498.

Suárez-Rodríguez M, López-Rull I, and Macias Garcia C (2013) Incorporation of cigarette butts into nests reduces nest ectoparasite load in urban birds: new ingredients for an old recipe? Biology Letters 9:20120931.

Walsh PT, Hansell M, Borello WD, and Healy SD (2010) Repeatability of nest morphology in African weaver birds. Biology Letters 6:149-151.

Wenzig EM, Widowitz U, Kunert O, Chrubasik S, Bucar F, Knauder E, and Bauer R (2008) Phytochemical composition and in vitro pharmacological activity of two rose hip (Rosa canina L.) preparations. Phytomedicine $15: 826-835$.

Wimberger PH (1984) The use of green plant material in bird nests to avoid ectoparasites. The Auk 101:615-618. 